\title{
Gibrat's Law in marketing: The case of liquor brand sales *
}

\author{
Adrian E. Tschoegl ** \\ Graduate School of Business Administration, The University of \\ Michigan, Ann Arbor, MI 48109-1234, USA \\ Chwo-Ming J. Yu \\ College of Commerce and Business Administration, University of \\ Illinois at Urbana-Champaign, Champaign, IL 61820, USA
}

We test the applicability of Gibrat's Law in the liquor brand market. Basically, we model annual changes in the unit sales of the top fifty liquor brands as white noise. Our results reject this model, but we do find that changes in sales are independent of starting market sales. This leads to the interpretation that brands with above average market share do not tend to gain market share, i.e., initial markc: share does not affect the subsequent change in market share. Furthermore, brands with above average sales do not have more stable sales than do firms with below average sales. Changes in sales appear highly positively correlated between periods, i.e., brands that gain sales in one period tend to gain sales in the next. Finally, no major liquor type or manufacturer had consistently and significantly greater or lower success across our various annual time periods.

\section{Introduction}

This study investigates the hypothesis that liquor brand sales follow Gibrat's Law (1931).

* We would like to thank Clifford Ball, C. Merle Crawford, Gregory Niehaus, Michael Ryan, and Edward Snyder for helpful comments on an earlier draft. We would also like to thank three anonymous reviewers for their comments. Responding to their suggestions improved the paper noticeably, though of course they are not responsible for any remaining flaws.

* * Present affiliation: SBCI Securities (Asia) Ltd., Tokyo Branch, Chiyoda-Ku. Tokyo 100, Japan.

Intern. J. of Research in Marketing 7 (1990) 249-262

North-Holland
Gibrat's Law as it was originally formulated hypothesizes that the growth rates of firms over a certain period of time are independent of their initial sizes, and thus the observed growth or decline of firms is the result of a large number of factors acting independently of each other. Although rtal world markets do not conform exactly to this law, various forms of evidence :uggest that one can model firm growth by simple stochastic processes (Prais, 1974). In the context of marketing, Gibrat's Law of Proportionate Growth states that the distribution of future growth rates of sales is the same for each brand in a product class, regardless of its prior level of sales or prior rate of growth of its sales. Because many researchers argue that market share is a key to reducing costs and thus to increasing profitability, and is a major variable in determining strategies, Gibrat's Law has implications for managers.

The significance of market share has attracted the attention of both firms and academic researchers. Many studies have tried to determine the relationship, if any, between market share and profitability (see, e.g., Buzzell, Gale and Sultan, 1975; Jacobson and Aaker, 1985; Cook, 1985). Other studies explore the determinants of market share (see, e.g., Karnani, 1983). Studies also exist which investigate the issue of model specification to evaluate the determinants of market share (Brodie and de Kluyver, 1984; Ghosh, Neslin and Shoemaker, 1984; Leeflang and Reuyl, 1984; Naert and Weverbergh, 1985). Though numerous studies support the notion that there is a positive relationship between market share and profit rate, non-confirming evidence also exists (Buzzell, 1981; Mancke, 1974; Rumelt and Wensley, 1981). 
Gibrat's Law provides another perspective on the determination of market share. Instead of hypothesizing that market share is determined by strategic factors, it argues that market structure is determined by certain stochastic processes. Empirical testing of the applicability of Gibrat's Law in marketing can not only shed new light on the market share-profitability controversy but also generate strategic implications for marketing managers.

The remainder of the paper is organized as follows. In Section 2 we discuss the possible link between Gibrat's Law and market share. In Section 3 we discuss the model and its implications. In Sections 4 and 5 we present the results for two different tests. Section 6 concludes the paper.

\section{Gibrat's Law and the determination of market share}

Gibrat's Law has drawn considerable attention over the years with respect to the effects of firm size. We are aware of over forty articles and books on the topic. Mostly, the authors have focused on all firms, the largest firms, or firms in a number of industries in a single country. The countries involved in these studies include Australia, Austria, Germany, Mexico, Sweden, South Africa, the United Kingdom and the United States. One recent example is Tschoegl's (1983) investigation of size, growth and transnationality among the world's largest banks.

In general, the evidence is contradictory with respect to the independence of growth rates and firm size. Depending on the sample, country, period, measure of size, or statistical methodology, independence is rejected as often as it is supported. When the studies reject independence, the finding that larger firms grew more quickly than smaller ones is as likely as the reverse. The studies commonly find that the growth rates of large firms are less variable than those of smaller firms, and there is positive serial correlation in growth rates uver adjacent periods.

The applicability of Gibrat's Law to market share can be argued on four grounds. First, Rothblum and Winter (1985) prove analytically that Gibrat's Law implies that the asymptotic probability distribution of the market shares of firms (brands) gives each firm (brand) an equal probability of dominating the market [while all other firms (brands) are almost extinguished], regardless of initial market share. Rothblum and Winter also demonstrate that the sample paths may fluctuate very slowly between near domination and near extinction.

Second, Padburg (1962) argues that stochastic models appear to be appropriate whenever growth is largely governed by environmental factors. As Bagozzi (1984) points out, there are a large number of determinants of market share, many of which are environmental. Orstein and Hanssens (1985) found that a number of economic, sociodemographic and regulatory factors affected the demand for spirits in general. The twentyeight variables they used in their study included price measures, aggregate consumption statistics, religious affiliation measures, age distribution statistics, Sunday blue law and minimum age measures, and others. Orstein and Hanssens (1985) found that beer and spirits reacted differently to changes in these variables. Presumably, within the spirits category itself there would be differences in reactions.

Third, there are studies suggesting that such factors as economies of scale and/or market power are much less important than stochastic growth processes to explain the association of market share and business profitability (Mancke, 1974; Rumelt and Wensley, 1981). In fact, Simon and Bonini (1958) argued that industry structures are determined by some stochastic growth processes. There is a whole family of stochastic growth processes with the 
characteristic that a firm's size in the next period is proportionate, subject to random variation, to its current size (Ijiri and Simon, 1977). All these processes can generate the skewed distributions of firm size in real-world industries. Among these distributions, Gibrat distribution, Pareto distribution, Yule distribution, and log-normal distribution have been tested. Other dynamic processes, lacking the proportionate growth property, exist but they typically fail to generate firm size distributions resembling those most frequently encountered in the real world (Scherer, 1980).

Fourth, research pioneered by Kuehn (1962) and continued by Bass (1974), Bass et al. (1984) and others indicates that consimer brand choice behavior is substantially stochastic. Of course, one must make further assumptions if one wishes to infer aggregate behavior from individual behavior.

In our literature review, we found only two papers in the marketing literature which address Gibrat's Law (Buzzell, 1981; Buzzell and Wiersema, 1981). Even though their unit of analysis differs from ours, we will discuss these two articles briefly, because they have appeared in the marketing literature, and because the results challenge our hypothesis.

Buzzell and Wiersema base their research on the PIMs data base on business units which may encompass several brands, or products within a brand. Buzzell (1981) found that average growth rates were systematically lower for business units with large market shares than for business units with small shares. However, there was one exception to this result: in very rapidly growing markets, growth rate was independent of starting share. Buzzell and Wiersema (1981) confirmed the negative relationship between market share change and the beginning level of market share in a series of multiple regression incorporating other factors.

One problem with the PIMS data is its survivorship bias. Business units with small market shares will tend to have extremely variable growth rates. This is due to a lack of diversification acre $s$ geographic markets whose economics conditions tend to be less than perfectly positively correlated. One can expect a large number to fail and withdraw from the market. The data base may not incorporate these failures, and thus the mean growth rate of the survivors will appear higher than that of business units with large market shares and low failure rates. However, rapidly growing markets are particularly forgiving in the sense that poor firm performance tends to manifest itself as an opportunity loss rather than actual failure. Thus, we can expect low failure rates in these markets at all levels of market share and, consequently, less survivorship bias.

Our work differs from the above by focusing on best-selling brands of one product. We investigate the applicability of Gibrat's Law to liquor brand sales over the period 1970 1987 , using cases sold as the measure of sales. We have chosen liquor brands primarily because of the ready availability of data over a long period; we discuss the data in greater detail in Section 4 below. In addition, we have examined three hypotheses about growth, where Hypothesis 1 is similar to the one investigated by Buzzell and Wiersema (1981).

\section{The model and its implications}

Following Vining, Jr. (1976), Rothblum and Winter (1985) and others, we assume the model of product sales growth to be

$S(i, t+1)=S^{\beta}(i, t) \exp \{\mu(i, t+1)\}$,

where $S(i, t)$ is the sales of product $i$ through period $t ; \beta$ is a growth parameter; and $\mu(i, t$ +1 ) is product $i$ 's draw from the common 
distribution of growth rates. ${ }^{1}$ There are $M$ products, so $i=1,2, \ldots, M$. We hypothesize that

$\mu(i, t+1) \sim \mathrm{N}\left(\alpha(t+1), \sigma^{2}\right)$.

Therefore,

$\mu(i, t+1)=\alpha(t+1)+\varepsilon(i, t+1)$,

where

$E[\varepsilon(i, t+1)]=0$.

Taking the logarithm of equation (1), we get the following cross-sectional relationship:

$$
\begin{aligned}
\ln S(i, t+1)= & \beta \ln S(i, t)+\alpha(t+1) \\
& +\varepsilon(i, t+1) .
\end{aligned}
$$

Gibrat's Law is equivalent to the following three null hypotheses.

Hypothesis 1 (H1). $\beta=1$.

Hypothesis 2 (H2).

$E\left[\varepsilon^{2}(i, t+1)\right]=\sigma^{2}(t+1)$.

Hypothesis 3 (H3).

$\operatorname{Cov}(\varepsilon(i, t+1), \varepsilon(i, t))=0$.

Thus, the null hypotheses result in a model of changes in growth rates across products and across time as white noise, and the logarithm of sales as following a random walk with drift. Two points follow immediately. First, the constant term $\alpha$ adjusts for industry-wide effects-whether industry sales are growing or declining. For example, $\alpha$ should be negative for the liquor industry because of its constant decline in sales. Second, $\beta$ is identical to the $\beta$ from the market share regression

$$
\begin{aligned}
\ln P(i, t+1)= & \gamma(t+1)+\beta \ln P(i, t) \\
& +\varepsilon(i, t+1),
\end{aligned}
$$

\footnotetext{
1 This is a typical assumption of testing Gibrat's Law. Empirical studies on the size of firms do not reject the notion that the distribution of growth rates in a given size class is the same for all size classes (Ijiri and Simon, 1977; Droucopoulos, 1982).
}

where

$$
P(i, t)=S(i, t) / \sum_{i} S(i, t)
$$

Therefore, $\beta$ is the elasticity of end-of-period market share with respect to start-of-period market share. Thus, by looking at sales we are in fact looking at market share. This concept is important in our analysis, because the discussion focuses on market share.

It is important to mention that equation (2) only implies or is consistent with equation (3) when $\beta=1$. When $\beta \neq 1$, equations (2) and (3) are inconsistent. However, equation (3) remains a useful and correct measurement model of the elasticity of end-of-period market share with respect to start-of-period market share.

If $\mathrm{H} 1$ holds, i.e., $\beta=1$, then, over time, the distribution of liquor brand market share will become highly skewed and concentration will increase. This result is a consequence of the random variation in growth rates. That is,

$$
\begin{gathered}
\operatorname{Var}(\ln S(i, t+1)) / \operatorname{Var}(\ln S(i, t)) \\
=\beta^{2}+\left[\sigma^{2} / \operatorname{Var}(\ln S(i, t))\right] .
\end{gathered}
$$

Even if $\beta=1$, dispersion of shares will increase as long as $\sigma^{2}>0$.

If $\mathrm{H} 1$ does not hold and $\beta$ is greater than 1 , then brands with larger sales (market shares) grow faster than brands with smaller ones. Thus, concentration will increase more rapidly than when $\beta=1$. Contrary to intuition, the fact that sales of small volume brands grow faster than the sales of larger volume brands $(\beta<1)$ does not itecessarily mean that concentration will tend to decrease over time. Whether concentration decreases or not also depends on the magnitude of $r^{2}$, where $r^{2}$ is the square of the correlation coefficient of the correlation between $\ln S(i, t)$ and $\ln S(i, t+$ 1). Simple algebraic manipulation of equation (4) and the definition of the correlation coef- 
ficient shows that

$\operatorname{Var}(\ln S(i, t+1)) / \operatorname{Var}(\ln S(i, t))=\beta^{2} / r^{2}$

We can estimate the ratio with the sample estimates $\hat{\beta}^{2} / R^{2}$, where $R^{2}$ is the coefficient of determination from the estimation of equation (2). If $\hat{\beta}<1$, dispersion will decrease only if $\sigma^{2}$ is small enough so that $R^{2}$ is larger than $\hat{\beta}^{2}$.

Besides the impact on industry concentration, $\mathrm{H} 1$ has implications for performance evaluation and strategic design. Market share is conventionally used as an indication of performance, with a high share indicating better performance. This leads to the conclusion that successful firms are those with large market shares. This reasoning would not hold if $\beta=1$. In this case, the level of market share is an inappropriate measure by which to evaluate a brand's performance. Higher market share may indicate success but does not imply better performance. Some brands will enjoy larger shares than other brands by chance, and thus market share in and of itself has no effect on performance. Other evaluation criteria for performance evaluation are necessary. If we accept $\mathrm{H} 1$ in the liquor market, the link between market share and strategies to gain it is questionable. Questing after market share in the belief that it leads to faster growth would appear to be an inappropriate strategy. Furthermore, because market share gains are not directly related to marketing strategies, brands seeking market shares through heavy investment may be the ones with low profit rates.

When $\beta \neq 1$, the strategic implications differ for big brands and small brands. If $\beta>1$, this is evidence for brand economies of scale, i.e., advantages to market share. Thus, a large market share leads to a higher growth rate. The existing literature on strategies to build up market share is more applicable to brands with large market share. For brands with small market share, increasing share quickly (e.g., through mergers and acquisitions) or engaging in activities to improve other aspects of the brands are preferred strategies. On the other hand, if $\beta<1$, small brands grow faster than large brands. This would indicate that, if market share is the objective, share-building strategies are more effective for brands with small shares. This may be the reason why many firms with low market share survive and even prosper (Wood and Cooper, 1982). For firms with large brands, introducing new brands to the market is a viable strategy to increase the aggregate market share of firms.

$\mathrm{H} 2$ provides a test of the contribution of market share to the stability of sales volume. If $\mathrm{H} 2$ holds, the variance of growth rates is the same for liquor brands with different sales volume. Then one cannot assume that the unit sales stream of any one brand is more or less stable than that of other brands. Rejecting $\mathrm{H} 2$, however, would indicate that brands with greater unit sales do have more stable growth rates than brands with lower unit sales.

H3 provides a test of the competitiveness of the liquor brand market. Consistently positively serially correlated growth implies that advantages acquired in one period can carry over to the next. This indicates that the advantages, either created by marketing programs or management skills, have an enduring effect. If these advantages represent monopolistic access to factors leading to faster growth, a low or zero degree of positive serial correlation implies that such access erodes quickly (Ijiri and Simon, 197). Consistently negatively serially correlated growth would imply the existence of some process or mechanism that systematically reverses fortune.

If we reject $\mathrm{H} 3$ for liquor brands, the implication for managers would be that marketing matters, because it is the carry-over of Successful brand marketing programs that creates the persistent above average growth. Therefore, devoting resources to improving 
marketing activities pays off. If we do not reject $\mathrm{H3}$, one can infer that advantages erode quickly, presumably because competitors are able to imitate innovators' strategies, and that marketing efforts have little lasting net effect given the marketing efforts of competitors. This would imply that "follow-the-brandleader" is an effective competitive strategy.

\section{Cross-sectional results}

We base our analysis on the report of liquor brand sales (rounded to the nearest 25,000 mixed cases) which Business Week (1970-1987) publishes annually. We estimate our basic equation [equation (9) below] for sixteen one-year periods. For each period, we use the top fifty brands at the start of the period in our analysis if the data are available.

To derive a model for estimation, we rearrange equation (2), taking into account the possibility of first-order serial correlation in growth rates (i.e., H3). This is done to avoid bias due to autocorrelations in the presence of lagged dependent variables (Chesher, 1979). The following model results:

$$
\begin{aligned}
\ln S(i, t+1)= & \alpha(t+1)+\beta \ln S(i, t) \\
& +\rho u(i, t)+\varepsilon(i, t+1),
\end{aligned}
$$

where $\rho$ is the serial correlation coefficient; $u(i, t)=\rho u(i, t-1)+\varepsilon(i, t)$; and $\varepsilon(i, t)$ is the standard stochastic error term. Since we can write $u(i, t)$ in terms of lagged values, equation (6) becomes

$$
\begin{aligned}
\ln S(i, t+1)= & b 0+b 1 \ln S(i, t) \\
& +b 2 \ln S(i, t-1) \\
& +\varepsilon(i, t+1),
\end{aligned}
$$

where

$$
\begin{aligned}
& b 0=\alpha(t+1)-\rho \alpha(t) \\
& b 1=\beta+\rho \\
& b 2=-\beta \rho
\end{aligned}
$$

$\rho$ is the serial correlation coefficient, and $\varepsilon$ is the serially uncorrelated error term. To recover $\beta$ and $\rho$, we solve the quadratic equation $x^{2}-\hat{b} 1 x-\hat{b} 2=0$. It has two solutions. Following Chesher (1979), we take the solution closest to one as the estimate of $\beta$, and the solution closest to zero as the estimate of $\rho{ }^{2}$ The inclusion of $\ln S(i, t)$ and $\ln S(i, t$ $-1)$ in the same regression raises the possibility of multi-collinearity. Multi-collinearity did not turn out to be a problem in the estimation, as we discuss below.

To reduce numerical problems due to multi-collinearity, we add and subtract $\beta p \ln S(i, t)$ from the right-hand side of equation (6). Rearranging terms results in equation (8), a modified version of equation (7):

$$
\begin{aligned}
& \ln S(i, t+1) \\
&= b 0+b 3 \ln S(i, t) \\
&+b 2[\ln S(i, t-1)-\ln S(i, t)] \\
&+\varepsilon(i, t+1) .
\end{aligned}
$$

Now $b 3=\beta+\rho-\beta \rho$, and $b 2$ still equals $-\beta \rho$. While mathematically identical to equation (7), equation (8) has a much lower correlation between its first two explanatory variables. Equation (8) therefore has a substantially reduced condition index for the matrix of explanatory variables, indicating a reduction in apparent multicollinearity (Belsley, Kuh and Welsch, 1980). ${ }^{3}$

We augment equation (8) by adding two sets of dummy variables to take into account

${ }^{2}$ Chesher (1979) made this suggestion by appealing to the literature on stochastic theory of the firm, where it is argued that $\beta$ is close to unity even if Gibrat's Law is not in operation.

${ }^{3}$ In a least squares regression, $\hat{\beta}=\left(X^{\prime} X\right)^{-1} X^{\prime} Y$. A high degree of multi-collinearity implies that at least one of the characteristic roots of $\left(X^{\prime} X\right)$ is very small. Be sley, Kuh and Welsch (1980) suggested using the square root of the ratio of the largest to the smallest characteristic root as a measure of multi-collinearity. This measure, termed a "condition index", indicates that multi-collinearity is a problem when the value exceeds 30. 
the impact on sales growth of certain other factors. The first set consists of five dummy variables representing different classes of products:

- Brandy and Cognac (BRA);

- Canadian whiskey (CAN);

- Scotch (SCO);

- Tennessee, Bourbon and Blended whiskey (TEN); and

- specialty liquors (SPE) (from 1976 on).

The omitted category includes rum, vodka, gin and tequila. We incorporate the variables to ensure that the differing fortunes of classes of spirits do not bias our results. As consumers are turning away from one class of spirits to another, dummy variables can control their effect on growth rates.

The second set of dummy variables consists of six variables representing different firms. Brand success may depend not so much on brand marketing as on the parent firm's marketing ability. More than rwenty firms manufacture the brands in our studies. Among them, the following six firms consistently have more than three brands in each year:

- Brown-Forman, Inc. (BF),

- Heublein, Inc. (HEU),

- National Distillers Products Co. (NAT),

- Schenley Industries, Inc. (SCH),

- Seagram Co. (SEA), and

- Walker (Hiram)-Resources, Ltd. (WAL).

The model for Ordinary Least Squares (OLS) estimation becomes

$$
\begin{aligned}
\ln S & (i, t+1) \\
= & b 0+b 3 \ln S(i, t) \\
& +b 2[\ln S(i, t-1)-\ln S(i, t)] \\
& +\sum_{j=1}^{5} a\left(j ; D(j, i)+\sum_{k=1}^{6} c(k) D(k, i)\right. \\
& +\varepsilon(i, t+1)
\end{aligned}
$$

where $D(j, i)$ represents brand $i$ belonging to product class $j(j=1,2, \ldots, 5)$, and $D(k, i)$ represents brand $i$ belonging to firm $k(k=1,2, \ldots, 6)$.
We apply the model to sixteen periods involving one-year intervals. We estimate the sixteen one-year interval regressions separately for several reasons. First, separating the periods enables us to check the temporal stability of the coefficients. The second reason we do not pool the data is that we have a knife-edge and extreme hypothesis (Ijiri and Simon, 1977). If we were to pool the data, the increase in degrees of freedom would mean that we would almost certainly reject $\mathrm{H} 1$ (Royall, 1986). We would be reducing the probability of a Type II error, while leaving the probability of a Type I error unchanged. Pooling would only be appropriate if we had a greatly asymmetric loss function (Quandt, 1980; Leamer, 1978). And, finally, the hypothesis of equality of intercepts and slopes for all of the sixteen periods is tested using an $F$-test. The computed $F$-value is significant at $1 \%$, which rejects the hypothesis of overall homogeneity.

Table 1 presents the results for the estimation of $\beta$ and $\rho$ and the regression statistics. The coefficients and regression statistics come from ols estimation of equation (9). We test the three hypotheses: (1) $\beta=1$, (2) $\rho=0$, and (3) $\beta=1$ and $\rho=0$ by performing oLs on the unconstrained and on the three constrained versions of equation (9), and then performing $F$-tests on the sums of the squared residuals. The numbers in parentheses in Table 1 are the $F$-statistics for the tests of the three hypotheses.

It is clear that in each period the estimated value oi $\beta$ is not significantly different from one. Nor do we observe any pattern across years. The mean value for $\beta$ across the fifteen years for which we have an estimate is 1.00 . In one period (1974-1975), we were unable to generate real roots to the quadratic equation for recovering $\beta$ and $\rho$. In all fifteen estimations, the $F$-statistics do not reject the null hypothesis that $\beta=1$.

Furthermore, we ranked the cases in each estimation by sales in the middle year. The 
Iable 1

Regression results for equation (9) (numbers in parentheses are $F$-statistics for the three hypotheses: (1) $\beta=1,(2) \rho=0$, and (3) $\beta=1$ and $\rho=0$ )

\begin{tabular}{|c|c|c|c|c|c|c|c|}
\hline Period & $\beta$ & $\rho$ & $\beta$ and $\rho$ & $R^{2}$ & SER & DW & $\begin{array}{l}\text { Number of } \\
\text { cases }\end{array}$ \\
\hline $1971-1972$ & $\begin{array}{c}0.982 \\
(0.706)\end{array}$ & $\begin{array}{r}0.435 \\
\left(12.2^{*}\right)\end{array}$ & $\left(6.45^{*}\right)$ & 3.995 & 0.050 & 2.40 & 50 \\
\hline $1972-1973$ & $\begin{array}{c}0.983 \\
(0.244)\end{array}$ & $\begin{array}{r}0.667 \\
\left(23.6^{*}\right)\end{array}$ & $\left(12.1^{*}\right)$ & 0.995 & 0.050 & 2.04 & 52 \\
\hline $1973-1974$ & $\begin{array}{c}1.01 \\
(0.183)\end{array}$ & $\begin{array}{r}0.533 \\
\left(28.0^{*}\right)\end{array}$ & $\left(14.4^{*}\right)$ & 0.997 & 0.37 & 2.40 & 50 \\
\hline $1974-1975$ & $\begin{array}{l}\text { na }^{a} \\
(0.889)\end{array}$ & $\begin{array}{l}\text { na } \\
\left(28.1^{*}\right)\end{array}$ & $\left(15.1^{*}\right)$ & 0.994 & 0.056 & 1.75 & 53 \\
\hline $1975-1976$ & $\begin{array}{c}1.09 \\
(3.60)\end{array}$ & $\begin{array}{r}0.597 \\
\left(21.8^{*}\right)\end{array}$ & $\left(11.3^{*}\right)$ & 0.990 & 0.071 & 2.02 & 49 \\
\hline $1976-1977$ & $\begin{array}{c}1.04 \\
(3.80)\end{array}$ & $\begin{array}{c}0.211 \\
\left(7.78^{*}\right)\end{array}$ & $\left(6.26^{*}\right)$ & 0.993 & 0.059 & 2.21 & 50 \\
\hline $1977-1978$ & $\begin{array}{c}0.916 \\
(0.038)\end{array}$ & $\begin{array}{r}0.845 \\
\left(25.6^{*}\right)\end{array}$ & $(14.9 *)$ & 0.991 & 0.069 & 2.00 & 50 \\
\hline $1978-1979$ & $\begin{array}{c}1.08 \\
(3.20)\end{array}$ & $\begin{array}{r}0.664 \\
\left(38.6^{*}\right)\end{array}$ & $\left(22.1^{*}\right)$ & 0.993 & 0.060 & 2.37 & 50 \\
\hline $1979-1980$ & $\begin{array}{c}0.984 \\
(0.138)\end{array}$ & $\begin{array}{r}0.590 \\
\left(22.8^{*}\right)\end{array}$ & $(11.7 *)$ & 0.990 & 0.072 & 1.60 & 51 \\
\hline $1980-1981$ & $\begin{array}{c}0.994 \\
(0.077)\end{array}$ & $\begin{array}{r}0.381 \\
\left(12.1^{*}\right)\end{array}$ & $\left(6.23^{i i}\right)$ & 0.994 & 0.058 & 1.99 & 50 \\
\hline $1981-1982$ & $\begin{array}{c}0.962 \\
(1.67)\end{array}$ & $\begin{array}{r}0.506 \\
\left(23.8^{*}\right)\end{array}$ & $\left(14.7^{*}\right)$ & 0.993 & 0.059 & 1.57 & 50 \\
\hline $1982-1983$ & $\begin{array}{l}1.00 \\
(0)\end{array}$ & $\begin{array}{r}0.451 \\
\left(11.8^{*}\right)\end{array}$ & $\left(6.26^{*}\right)$ & 0.987 & 0.080 & 2.19 & 50 \\
\hline 1983-1984 & $\begin{array}{c}1.03 \\
(0.381)\end{array}$ & $\begin{array}{c}0.385 \\
\left(7.24^{*}\right)\end{array}$ & $\left(3.84^{*}\right)$ & 0.979 & 0.105 & 1.81 & 51 \\
\hline 1984-1985 & $\begin{array}{c}0.989 \\
(0.290)\end{array}$ & $\begin{array}{c}0.105 \\
(0.963)\end{array}$ & $(0.576)$ & 0.989 & 0.074 & 1.85 & 53 \\
\hline $1985-1986$ & $\begin{array}{c}0.991 \\
(0.113)\end{array}$ & $\begin{array}{r}0.288 \\
\left(22.9^{*}\right)\end{array}$ & $\left(12.1^{*}\right)$ & 0.989 & 0.078 & 2.06 & 50 \\
\hline 1986-1987 & $\begin{array}{c}0.999 \\
(0.002)\end{array}$ & $\begin{array}{c}0.226 \\
\left(5.27^{*}\right)\end{array}$ & $(2.82 * *)$ & 0.987 & 0.078 & 2.02 & 49 \\
\hline
\end{tabular}

a Not available.

* Significant at the $5 \%$ level.

** Significant at the $10 \%$ level.

Durbin-Watson (DW) statistic then has a cross-sectional interpretation, not a timeseries one, and provides a test of the linearity of $b$ 's in equation (9). ${ }^{4}$ Because the DW statistic is not significant in any of our tests, we continue to believe that the process does not differ from the highest to the lowest of

\footnotetext{
4 We can test the linearity of $b$ 's by determining whether the sequence of the deviations from the regression line is randomly arranged. If the residuals are arranged according to increasing values of $\ln S(i, t)$, the Durbin-Watson test can be used to check the linearity of $b$ 's (Kmenta, 1986).
}

our sample of brands, i.e., that the $\beta$ for smaller unit sales brands is the same as that for brands with larger unit sales. Thus, we do not reject our null hypothesis $\mathrm{H} 1$.

In all cases, the DW statistic fell in one (six cases) or both (seven cases) of the indeterminant regions of the test. Almost all of the cases where DW was in the indeterminant regions resulted from violations of the ols assumption that $\operatorname{Cov}\left(\varepsilon_{i, t}, \varepsilon_{j, t}\right)=0$, for $i \neq j$. Because we are dealing ultimately with market shares, the success of one brand may nega- 
Table 2

Signs of statisticaily significant vaiues ( $5 \%$ level) of the dummy variables in equation (y)

\begin{tabular}{|c|c|c|c|c|c|c|c|c|c|c|c|}
\hline Period & BRA & CAN & TEN & sco & SPE & HEU & BF & WAL & NAT & $\mathrm{SCH}$ & SEA \\
\hline 1971-1972 & & & - & $\overline{-}$ & & + & & + & & & \\
\hline $\begin{array}{l}1972-1973 \\
1973-1974\end{array}$ & & & & & & & & - & & & \\
\hline $\begin{array}{l}1973-1974 \\
1974-1975\end{array}$ & - & & & & & + & + & & & & + \\
\hline $\begin{array}{l}1974-1975 \\
1975-1976\end{array}$ & & - & & $\overline{+}$ & & & & & & & \\
\hline 1976-1977 & & & & - & & & + & & & + & \\
\hline $1977-1978$ & & & & + & & & & & & - & \\
\hline $1978-1979$ & & - & & & & & & & & + & \\
\hline \multicolumn{12}{|l|}{$1979-1980$} \\
\hline \multicolumn{12}{|l|}{$1980-1981$} \\
\hline $1981-1982$ & & & & & & & & & & & \\
\hline $1982-1983$ & & & & & & + & & & & & \\
\hline 1983-1984 & & & & & & & & - & & & \\
\hline 1984-1985 & & - & & & & & & & & & \\
\hline 1985-1986 & & & & & & + & & & & & \\
\hline $1986-1987$ & & & & & & & & & & & \\
\hline
\end{tabular}

tively affect that of another brand in the same segment. $^{5}$

Because we are dealing ultimately with market shares, we cannot eliminate all crosssectional correlation. Although cross-sectional correlation does not induce any bias, it does have two consequences. First, it prevents us from estimating Gibrat's Law within the confines of a single product segment such as the vodkas, or the gins. Second, like uncorrected serial correlation, cross-sectional correlation has the effect of causing an understatement of estimated standard errors, even though the coefficients estimated remain unbiased and consistent. Given the large number of covariances, many of which involve pairs of products that presumably compete only distantly with each other, the biasing effect on the standard errors may be small.

As mentioned earlier, the presence in the estimating equation of both $\ln S(i, t)$ and $\ln S(i, t-1)$ raises the possibility of problems with multi-collinearity. Because the con-

\footnotetext{
${ }^{5}$ We examined the studentized residuals from our estimations and isolated those cases where two or more brands in the same category had studentized residuals with an absolute value in excess of 2 , and opposite sign. We removed these brands and re-estimated the regressions. DW statistics improved and the estimates of $\beta$ and $\rho$ changed marginally.
}

dition indices of the matrix of (standardized) explanatory variables are all less than 4 , which is far less than the suggested criterion of 30 , multi-collinearity does not appear to be an issue.

Table 2 is a census of dummy variables significant at the $5 \%$ level from the regressions reported in Table 1 . No type of liquor or parent firm had consistently statistically significant above or below average performance. Five companies had at least one above average year, and only Heublein, Inc. had more than two.

We test $\mathrm{H} 2$ by using the Breusch-Pagan (1979) test for heteroscedasticity. A statistically significant $\chi^{2}$ statistic rejects the null hypothesis of homoscedasticity. We perform two tests. In the first test, we use $\ln S(i, t)$ as our only independent variable. As Table 3 shows, the test rejects homoscedasticity in five out of sixteen cases. In the second test, we include all the independent variables from equation (9). In this case, the test fails to reject homoscedasticity in all cases. The heteroscedasticity that does exist is most often associated with class of liquor and parent firm, not magnitude of brand sales. Because our interest is equation (9), we fail to reject H2 in light of the test results. 
Table 3

Results for the Breusch-Pagan test for the residuals from equation (9)

\begin{tabular}{lllcl}
\hline Period & $\begin{array}{l}\chi^{2} \\
(\text { In } S(t))\end{array}$ & $\begin{array}{l}\text { Degrees } \\
\text { of } \\
\text { freedom }\end{array}$ & $\begin{array}{l}\chi^{2} \\
\text { (full } \\
\text { model) }\end{array}$ & $\begin{array}{l}\text { Degrees } \\
\text { of } \\
\text { freedom }\end{array}$ \\
\hline $1971-1972$ & $4.45^{*}$ & 1 & 17.7 & 12 \\
$1972-1973$ & $5.18^{*}$ & 1 & 7.51 & 12 \\
$1973-1974$ & $6.49^{*}$ & 1 & 8.10 & 12 \\
$1974-1975$ & $4.61^{*}$ & 1 & 13.49 & 12 \\
$1975-1976$ & 3.62 & 1 & 12.8 & 12 \\
$1976-1977$ & 0.816 & 1 & 10.6 & 13 \\
$1977-1978$ & 2.33 & 1 & 9.54 & 13 \\
$1978-1979$ & 0.488 & 1 & 14.9 & 13 \\
$1979-1980$ & 0.905 & 1 & 7.69 & 13 \\
$1980-1981$ & 3.70 & 1 & 9.58 & 13 \\
$1981-1982$ & 0.218 & 1 & 8.68 & 13 \\
$1982-1983$ & $4.01 *$ & 1 & 18.1 & 13 \\
$1983-1984$ & 2.01 & 1 & 7.66 & 13 \\
$1984-1985$ & 0.257 & 1 & 4.80 & 13 \\
$1985-1986$ & 1.23 & 1 & 11.4 & 13 \\
$1986-1987$ & 0.699 & 1 & 22.2 & 13 \\
\hline
\end{tabular}

* Significant at the $5 \%$ level.

The estimates of $\rho$ provide the test of $\mathrm{H} 3$. As Table 1 shows, the estimates of $p$ are always positive, and fifteen of the sxteen $F$-tests reje:t the hypothesis that $\rho=0$ This result reiects $H 3$. The mean value of $\rho$ for the fifteen years for which we have an estimate is 0.464 .

The test of the joint hypothesis $\beta=1$ and $\rho=0$ rejects the hypothesis. Examination of the relevant $F$-statistics in Table 1 and their comparison with the $F$-tests for the separate hypotheses indicates that rejection is due to the failure of H3. That is, sales growth is serially correlated.

We need to make one last test. Business Week reports the data only to the nearest 25,000 cases. As a result, the data are subject to an errors-in-variables problem. To check for bias due to errors-in-variables, we employ instrumental variables estimation. ${ }^{6}$ As be-

\footnotetext{
${ }^{6}$ Sales in any nearby year will be highly correlated with those in year $t$, but the rounding errors in the two years are likely to be uncorrelated. Therefore, we used sales for a yea: other than those in the estimation as the instrument for sales in year $t$. For example, we used sales in 1980 as the instrument for 1982 for the period of 1982-1983.
}

fore, the results are consistent with $\mathrm{H} 1$, and we were able to recover $\beta$ and $\rho$ for 1974 1975. The means of the estimates of $\beta$ and $\rho$ are 1.01 and 0.456 , respectively.

\section{Time-series results}

Our seventeen years of data involve some eighty brands. For thirty-one of the top fifty of these brands we have a full eighteen years of data. It is these thirty-one brands which we use in the test below. Using only those brands for which we have a long history may introduce a selection bias into our results. If so, we have no a priori reason to believe that the effect favors large or small sales volume brands. Other things being equal, we are more likely to have lost lower sales volume brands with more volatile sales than larger sales volume brands with proportionately equally variable sales.

The model we apply to the data is one much used in the econometric liternture. The model we estimate is

$$
\begin{aligned}
\Delta \ln S(i, t)= & B 0+B 1 \ln S(i, t-1) \\
& +\sum_{j=1}^{P} A(j) \Delta \ln S(i, t-j) \\
& +\sum_{k=1}^{4} C(k) D(k)+\varepsilon(i, t),
\end{aligned}
$$

where $\Delta$ is the difference operator, $P$ is the order of autoregression, and the $C(K)$ 's are $(1,0)$ dummy variables for classes of liquors. The classes of liquors reduce from five to four because specialty liquors are not represented in the thirty-one brands studied. Though we suspect the growth of liquor brand sales exhibits autoregressive dependence, we are nct able to determine the value of $P$. Wè examine $P$ from 0 to 5 . The model in equation (10) owes its origins to the work of Fuller (1976) and Dickey and Fuller (1979), who studied 


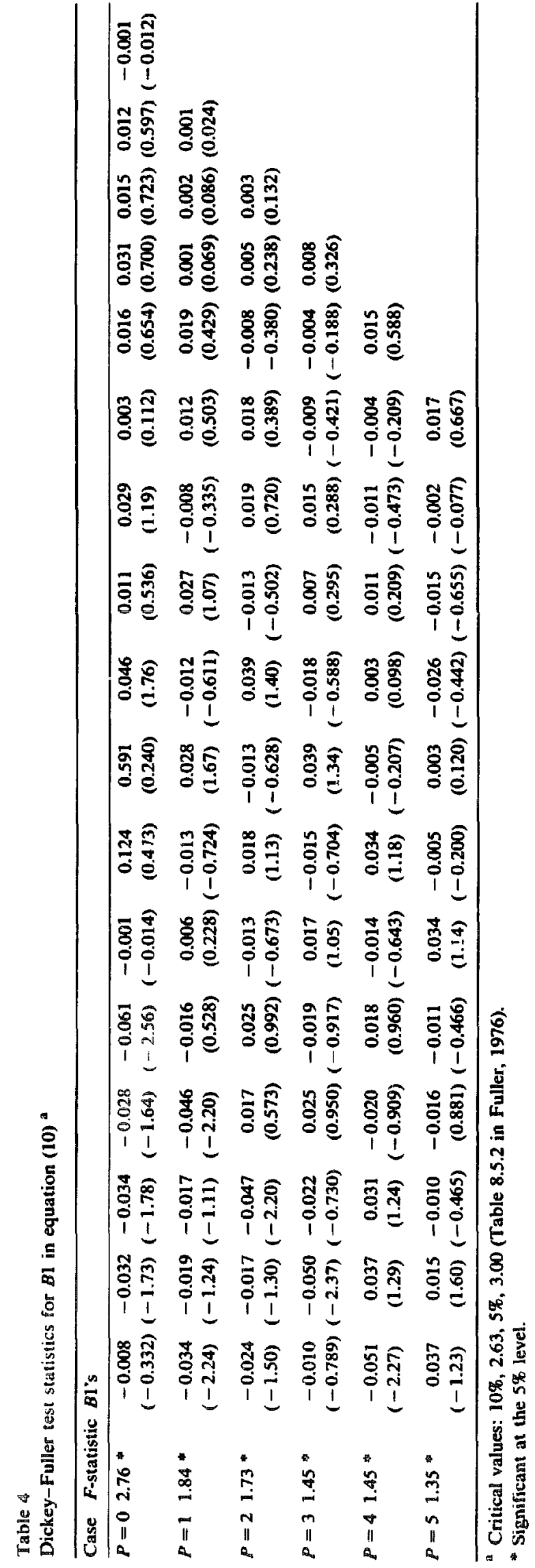


non-stationary autoregressive time series. One common application is to test whether economic time series such as GNP are stationary (see, e.g., Stock and Watson, 1986).

We use ors to estimate equation (10), with and without the dummy variables for classes of liquors. We can test the hypothesis $B 1=0$ by examining the (non-normally distributed) $t$-ratio for $B 1$, and comparing it to the values in Fuller's (1976) Table 8.5.2. Rearranging terms, i.e., adding $\ln S(i, t-1)$ to both sides, is sufficient to show that $B 1=0$ is the same hypothesis as $\beta=1$.

Table 4 presents the results for the model with the dummy variables. The first column reports the $F$-statistics for the test of pooling. Since the data are available for seventeen years, pooling all the cases together would increase the efficiency of estimation. The $F$ statistics are all statistically significant at the $5 \%$ level, indicating the inappropriateness of pooling. Therefore, the number of $B 1$ estimates differs for different values of $P$. For example, when $P=5$, there are twelve estimates of $B 1$. As Table 4 shows, the results do not reject the null hypothesis. That is, we accept $B 1=0$ and therefore $H 1: \beta=1$. Of course, this may be a function of the filtering effect of using only those brands for which we have complete data. We reach the same conclusion for the model which does not have the dummy variables for classes of liquors. Our results are inconsistent with Buzzell and Wiersema's (1981) results. However, in both our time-series test and Buzzell and Wiersema's cross-sectional test, a selection bias may be operating.

\section{Conclusion}

This study tested Gibrat's Law of Proportionate Growth for liquor brand sales for the top fifty brands in unit sales in the period of 1970 to 1986 . In each of the sixteen annual periods examined, the rate of growth of liquor brand sales, i.e., the rate of change of market share, was independent of the level of sales, i.e., the starting market share. The time-series test on the data for thirty-one brands still accepts the null hypothesis. Thus, we found no evidence for brand-level economies of scale.

Our cross-sectional and time-series results contradict those of Buzzell (1981) and Buzzell and Wiersema (1981). Further research is necessary to determine whether our results are the consequence of the chance choice of an atypical product, or if their results are an artifact of their data base.

Variation in growth rates was the same across liquor brands with different sales levels. Above average sales volume is not associated with more stable rates of growth. Because we are examining brands sold throughout the United States, differences in sales volume may not represent meaningful differences in geographical diversification.

However, individual brand sales growth or decline over a one-year period clearly carried over to the next period. Success (failure) in one year continued into the next year. This suggests that marketing matters, and not just as an anodyne to the marketing efforts of others. Successful marketing efforts lead to persistent market share growth. That is, market share growth leads to market share, not vice versa.

Finally, in not a single case did any type of liquor or parent firm have consistently statistically significant above or below average results across our sixteen one-year periods, though occasional coefficients were significant. In each period, a different company had the best performance.

In summary, our findings in the liquor brand market suggest that, as pointed out by Rumelt and Wensley $(1981$, p. 6):

Market share is not in itself a valid strategic goal ... business plans and strategies that have no en. trepreneurial content other than share-gain tactics are einpty. 
The results of our study also confirm the importance of marketing efforts in the liquor industry. The winning brands are the ones whose managers are constantly upgrading their marketing strategies.

Our results, though interesting and perhaps surprising, are based only on the top-selling brands of one type of product. The next step is to see if the results hold for a wider range of volumes, of for other products. The process may be different at very small volumes, or for new brands or products. Only by replicating this study for other products can we begin to assess for which types of products our results hold, and for which ones they do not.

This study investigates the determination of market share by a stochastic process. Though the focus is not the link between market share and profitability, we have discussed the possible impact on profit when Gibrat's Law does or does not apply. The next logical extension of the study is to examine the marketing strategies of liquor brands and the profitability of each brand. This will not only verify the arguments we made here but also help to identify strategic alternatives for cther products with similar industry characteristics.

\section{References}

Bagozzi, R.P., 1984. A prospectus for theory construction in marketing. Journal of Marketing 48, 11-29.

Bass, F.M., 1974. The theory of stochastic preference and brand switching. Journal of Marketing Research 11, 1-20.

Bass, F.M., M.M. Givon, M.U. Kalwani, D. Reibsteir and G.P. Wright, 1984. An investigation into the order of the brand choice process. Marketing Science 3, 257-287.

Belsley, D.A., E. Kuh and R.E. Welsch, 1980. Regression diagnostics. New York: Wiley.

Breusch, T.S. and A.R. Pagan, 1979. A simple test for heteroskedasticity and random coefficient variation. Econometrica 47, 1287-1294.

Brodie, R. and C.A. de Kluyver, 1984. Attraction versus linear and multiplicative market share models: An empirical evaluation. Journal of Marketing Research 21, 194-201.

Rusiness Week, 1970-1987. Various issues.
Buzzell, R.D., 1981. Are there 'natural' market shares? Journal of Marketing 45, 42-51.

Buzzell, R.D., B.T. Gale and R.G.M. Sultan. 1975. Market share-A key to profitability. Harvard Business Review 53, 97-106.

Buzzell, R.D. and F.D. Wiersema, 1981. Modelling changes in market share: A cross-sectional analysis. Strategic Management Journal 2, 27-42.

Chesher, A., 1979. Testing the law of proportionate growth effect. Journal of Industrial Economics 27, 403-411.

Cook, V.J., 1985. The net present value of market share. Journal of Marketing 49, 49-63.

Dickey, D.A. and W.A. Fuller, 1979. Distribution of the estimators for autoregressive time series with a unit root. Journal of the American Statistical Association 74 (366), 427-431.

Droucopoulos, V., 1982. International big business, 1957-77: A sequel on the relationship between size and growth. Journal of Economic Studies 19 (3), 3-19.

Fuller, W. s.. 1976. Introduction to statistical time series. New York: Wiley.

Ghosh, A., S. Neslin and R. Shoemaker, 1984. A comparison of market share models and estimation procedures. Journal of Marketing Research 21, 202-210.

Gibrat, R., 1931. Les inégalités économiques. Paris: Recueil Sirey. Extract available as: Gibrat, R. [1957]. On economic inequalities. International Economic Papers, New York: MacMillan.

Ijiri, Y. and H.A. Simon. 1977. Skew distributions and the sizes of business firms. Amsterdam: North-Holland.

Jacobson, R. and D.A. Aaker, 1985. Is market share all that it's cracked up to be. Journal of Marketing 49, 11-22.

Karnani, A., 1983. Minimum market share. Marketing Science $2,75-93$.

Kmenta, J., 1986. Elements of econometrics. New York: Macmillan.

Kuehn, A.A., 1962. Consumer brand choice as learning behavior. Journal of Advertising Research 2, 10-17.

Leamer, E.E., 1978. Specification searches. New York: Wiley.

Leeflang, P.S.H. and J.C. Reuyl, 1984. On the predictive power of market share attraction models. Journal of Marketing Research 21, 211-215.

Mancke, R.B., 1974. Causes of interfirm profitability differences: A new interpretation of the evidence. Quarterly Journal of Economics 88, 181-193.

Naert, Ph.A. and M. Weverbergh, 1985. Market share specification, estimation, and validation: Toward reconciling seemingly divergent views. Journal of Marketing Research 22, 453-461.

Orstein, S.I. and D. Hanssens, 1985. Alcohol control laws and the consumption of distilled spirits. Journal of Consumer Research 12, 200-213.

Padberg, D.I., 1962. The uses of Markov process in measuring changes in market structure. Journal of Farm Economics 44, 189-199.

Prais, S.J., 1974. A new look at the growth of industrial concentration. Oxford Economic Papers 26, 273-288.

Quandt, R.E., 1980. Classical and bayesian hypothesis testing: A compromise. Metroeconomica 32, 173-180. 
Rothblum, U.G. and S.G. Winter, 1985. Asymptotic behavior of market shares for a stochastic growth model. Journal of Economic Theory 36, 352-366.

Royall, R.M., 1986. The effect of sample size on the meaning of significance tests. The American Statistician 40, 313-315.

Rumelt, R.P. and R.C. Wensley, 1981. In search of the market share effect. In: K.H. Chung, (ed.), Academy of Management Proceedings '81, 2-6.

Scherer, F.M., 1980. Industrial market structure and economic performance. Chicago: Rand McNally.

Simon, H.A. and C.P. Bonini, 1958. The size distribution of business firms. American Economic Review 48, 607-617.
Stock, H. and M.W. Watson, 1986. Does GNP have a unit root? Economics Letters 22, 147-151.

Tschoegl, A.E., 1983. Size, growth, and transnationality among the world's largest banks. The Journal of Business 56, 187-201.

Vining, D.R., Jr., 1976. Autocorrelated growth rates and the Pareto law: A further analysis. Journal of Political Economy 84, 369-380.

Wood, C.Y. and A.C. Cooper, 1982. The surprising case for law market share business. Harvard Business Review 60, 106-113. 